RESEARCH PAPER

\title{
A prospective study of household smoking bans and subsequent cessation related behaviour: the role of stage of change
}

\author{
B A Pizacani, D P Martin, M J Stark, T D Koepsell, B Thompson, P Diehr
}

Tobacco Control 2004; 13:23-28

See end of article for authors' affiliations

.....................

Correspondence to: Dr Barbara A Pizacani, Department of Human Services, Office of Disease Prevention and

Epidemiology, $800 \mathrm{NE}$

Oregon Street, Suite 730

Portland, Oregon 97232,

USA; barbara.a.

pizacani@state.or.us

Received 3 January 2003

Accepted 21 August 2003

\begin{abstract}
Objective: To assess the degree to which smokers living with a full household ban on smoking change their cessation related behaviour.

Design, setting, and participants: Prospective cohort study; follow up of a population based cohort of 1133 smokers, identified from a 1997 telephone survey of adult Oregonians. After a median of 21 months, 565 were located and reinterviewed.

Main outcome measures: Quit attempts, time until relapse, and smoking cessation, defined as seven day and 90 day sustained abstinence at follow up.

Results: A full ban at baseline was associated with a doubling of the odds of a subsequent quit attempt (odds ratio $(O R)=2.0,95 \%$ confidence interval $(\mathrm{Cl}), 1.0$ to 3.9). Among respondents in the preparation stage at baseline (intention to quit in the next month with a quit attempt in the previous year), a full ban was associated with a lower relapse rate (hazard ratio $=0.5(95 \% \mathrm{Cl}, 0.2$ to 0.9$)$ ), while for those in precontemplation/contemplation (no intention to quit or intention to quit within the next six months, respectively), there was no significant association between full ban and relapse rate. For respondents in preparation, those with a full ban had over four times the odds of being in cessation for seven or more days before the follow up call $(O R=4.4(1.1$ to 18.7$))$, but for those in precontemplation/contemplation, full bans were unrelated to cessation.

Conclusions: Full household bans may facilitate cessation among smokers who are preparing to quit by increasing quit attempts. They may also prolong time to relapse among those smokers.
\end{abstract}

$\mathrm{T}$ he practice of restricting smoking inside the home is becoming more common in the USA as non-smokers learn of the hazards of exposure to secondhand smoke. ${ }^{1}$ Smoking restrictions in worksites have led several investigators to explore whether these rules help smokers cut down or quit. ${ }^{2}{ }^{3}$ Only a few studies, however, have explored whether smokers living in a household with smoking restrictions might quit smoking more often than those living without restrictions.

Two cross sectional reports from California have documented associations between bans and decreased amount smoked per day ${ }^{4}$ and greater interest in quitting. ${ }^{5}$ A national cross sectional study also showed an association between full household bans and quitting in the previous year. ${ }^{6}$ To date, however, we are unaware of any population based prospective data exploring whether smokers in a household with a ban actually change their smoking behaviour.

Our primary aim in this prospective study was to investigate the relation between household bans and smoking cessation. We were also interested in exploring whether household restrictions were associated with other cessation related behaviours such as the occurrence of a quit attempt and the length of quit attempts occurring during the follow up period. Previous work has shown that these behaviours are associated with a greater probability of eventual cessation $^{7-11}$ and are likely to confer health benefits. ${ }^{12}$ If a low cost population based intervention such as a household smoking ban proves beneficial at all steps in the quitting continuum, not just in the ultimate step of cessation, it may be of significant use for clinicians, public health advocates, and individual non-smokers in discouraging smoking.

\section{METHODS}

\section{Baseline survey}

Between August and November 1997, a population based cross sectional telephone survey of 6199 adult English speaking Oregonians was carried out to provide information on smoking prevalence in the Oregon population and on knowledge and attitudes toward tobacco. Methods for the baseline study have been described previously. ${ }^{13}$

\section{Follow up survey}

In 1999, we conducted a follow up study of 1604 persons who were smokers or living in a household with at least one smoker, at the 1997 baseline survey. The median time to follow up was 21.3 months. A standardised questionnaire was administered by telephone and included questions on tobacco attitudes and practices. Average interview length was approximately 12 minutes. This analysis focused on 1133 respondents who were regular or occasional smokers at baseline. A smoker was defined as having smoked at least 100 cigarettes during their lifetime, and answering "every day" or "some days" to the question, "Do you now smoke cigarettes every day, some days or not at all?".

Of the 1133 baseline smokers who were eligible for follow up (that is, who agreed to being recontacted and had information on home smoking bans), 583 completed interviews during two waves of call-backs-a response rate of $51.5 \%$. The $48.5 \%$ loss to follow up was comprised of $10.2 \%$ refusals and $38.3 \%$ inability to locate the respondent. Of the 583 final cohort members, 18 were excluded from all analyses as they classified themselves as regular smokers at baseline and as never smokers at follow up. 


\section{Measures}

We used data from the baseline survey to classify smokers according to their level of household smoking restriction using the following question: "Which of the following statements best describes the rules about smoking inside your home: ( 1 ) no one is allowed to smoke anywhere inside your home (full ban); (2) smoking is allowed in some places or at some times (partial ban); (3) smoking is permitted anywhere inside your home (no ban)."

We examined three outcomes: the occurrence of a quit attempt for at least one day before follow up; the time until relapse to smoking or follow up call; and cessation from smoking, defined as seven day and 90 day sustained abstinence at follow up.

Respondents who were abstinent at follow up (quitters) answered "not at all" to the follow up interview question, "Do you now smoke cigarettes every day, some days, or not at all?" To assess time since last cigarette, we used the question, "What was the date that you last smoked, even a single puff, on a cigarette?". We assessed quitters using two definitions: those whose last puff was seven or more days before the follow up interview, or 90 or more days before follow up. Quitters whose time of last puff was less than seven days or less than 90 days were excluded from the relevant analysis rather than combined with the comparison group, as they may have eventually exceeded their observed periods of abstinence.

Quitting activity since the baseline interview among those still smoking at follow up was ascertained by asking the question, "Since we talked in the fall of 1997, about how many times have you quit smoking intentionally for 24 hours or longer?" Respondents who were abstinent at follow up were also credited with a quit attempt.

We examined the duration of quit attempts in order to determine whether household restrictions were related to relapse rates. We used the most recent attempt if there was more than one during the follow up period, and ascertained its length by asking, "For your most recent quit attempt, what is the total amount of time you did not smoke?" For quitters, we used time since last puff for duration of abstinence.

Information from the baseline survey was used to adjust for potential confounders (age, sex, race, educational level, employment status, presence of children under 18 in the household, baseline cigarette consumption, and stage of change). The stage of change model ${ }^{14}{ }^{15}$ classifies smokers into the precontemplation, contemplation, or the preparation stage with respect to quit intention. Smokers in the precontemplation stage were not thinking of quitting smoking within the next six months at the baseline interview. Smokers in the contemplation stage were considering quitting in the next six months, and those in the preparation stage were considering quitting in the next 30 days and had a quit attempt of at least one day in the year before baseline. Smokers with an intention to quit in the next 30 days but who did had had a quit attempt in the previous year were classified as contemplators. In all analyses, we combined precontemplators with contemplators because of their similarities in addiction level and previous long term quit attempts. ${ }^{8}$ Furthermore, the preparation stage is differentiated by history of a quit attempt in the past year.

\section{Analysis}

We reweighted the follow up data, retaining factors affecting each respondent's probability of selection at baseline and adding a weighting class adjustment to adjust for loss to follow up. The weighting class adjustment was computed by calculating the probability of response by those baseline demographic characteristics most highly related to response rate, and using the inverse of this probability to adjust for response at follow up. ${ }^{16}{ }^{17}$ Finally, the data were poststratified to the 1997 age and sex distribution by county. We used Stata $6.0^{18}$ to carry out all analyses, a program which can account for complex survey designs and compute appropriately larger standard errors generated by such a design. We chose to use the odds ratio as a measure of association even though it is further from the null than the relative risk, as we were interested chiefly in the presence, direction, and relative strength of an association between smoking bans and smoking related outcomes. Adjusted Wald $\chi^{2}$ statistics were used to test for significance. All percentages presented in this paper are weighted, while counts are unweighted.

We also conducted Cox proportional hazards regression to examine whether household bans influenced the duration of quit attempts. The outcome for the analysis was defined as days until relapse to smoking occurred, and data for quitters were censored at the follow up interview. Although the analysis was done for the entire follow up period, we present Kaplan-Meier survival curves truncated at six months ( 180 days) to display better the earlier period of follow up where relapses were more frequent.

In all analyses, we chose to combine the no ban and partial ban categories because it is most relevant to study the effect of a full ban on smoking behaviour (full bans have been shown to be associated with fewer days of indoor smoking $^{13}$, and will probably more often be recommended as a public health measure). Also, in preliminary analyses, the pattern of association between partial bans and the outcomes under study was more similar to that of no ban than full ban.

\section{RESULTS}

We examined differences in baseline characteristics among respondents and non-respondents. We found that nonrespondents were significantly younger, more likely to be unmarried, to have lower annual household incomes, and to lack health insurance, but were similar to respondents with regard to sex, education and employment status, amount smoked, intention to quit smoking, and proportion having a full household smoking ban at baseline.

\section{Cohort characteristics by exposure group (partial or no ban $v$ full ban)}

Table 1 presents the baseline characteristics of final cohort members with full ban $v$ those with no ban or a partial ban. Smoking respondents with a full ban were younger $(\mathrm{p}<0.05)$, more likely to be non-white, to have higher incomes $(p<0.05)$ and more education, to be married, and to have children at home than the group of smokers with partial bans or no bans at all. They were also more likely to be in contemplation or preparation, and to be occasional smokers ( $\mathrm{p}<0.05$ for both).

\section{Household bans and quit attempts}

Of 565 baseline smokers, 371 (67\%) had quit for at least one day before follow up. This group comprised respondents who had quit but relapsed during the follow up period ( $\mathrm{n}=256$ ) and those who were in cessation at follow up $(n=115)$. Table 2 shows that those living with a full ban had twice the odds of a quit attempt lasting at least one day compared with those with no ban or a partial ban (odds ratio $(\mathrm{OR})=2.0$ (95\% confidence interval (CI) 1.0 to 3.9)). We also conducted an analysis restricted to those smokers who had quit but relapsed, and observed a similar association between household ban and quit attempts (data not shown). 
Table 1 Baseline cohort characteristics by household smoking restriction status*

\begin{tabular}{|c|c|c|}
\hline Characteristic & $\begin{array}{l}\text { No ban or partial } \\
\text { ban }(n=393)\end{array}$ & Full ban $(n=172)$ \\
\hline \multicolumn{3}{|l|}{ Employment status } \\
\hline Employed & 60.4 & 63.4 \\
\hline Unemployed & 5.9 & 7.3 \\
\hline Homemaker & 7.7 & 4.7 \\
\hline Student & 1.7 & 4.0 \\
\hline Retired & 20.1 & 14.4 \\
\hline Unable to work & 4.2 & 6.2 \\
\hline \multicolumn{3}{|l|}{ Education level } \\
\hline Less than high school & 13.9 & 8.9 \\
\hline High school graduate & 44.4 & 40.9 \\
\hline College 1 to 3 years & 28.1 & 35.2 \\
\hline College $4+$ years & 13.6 & 15.0 \\
\hline \multicolumn{3}{|l|}{ Marital status } \\
\hline Married/living together & 56.5 & 64.6 \\
\hline Divorced or separated & 18.2 & 17.4 \\
\hline Widowed & 11.8 & 4.1 \\
\hline Never married & 13.5 & 13.9 \\
\hline \multicolumn{3}{|l|}{ Household smoking } \\
\hline Smokers only & 61.3 & 51.4 \\
\hline Mixed & 38.7 & 48.6 \\
\hline \multicolumn{3}{|l|}{ Age (years)† } \\
\hline 18 to 24 & 7.6 & 7.8 \\
\hline 25 to 34 & 11.4 & 27.6 \\
\hline 35 to 44 & 28.2 & 22.9 \\
\hline 45 to 54 & 25.2 & 21.0 \\
\hline 55 to 64 & 11.3 & 14.4 \\
\hline $65+$ & 16.4 & 6.4 \\
\hline \multicolumn{3}{|l|}{ Race } \\
\hline White & 93.7 & 87.5 \\
\hline Non-white & 6.3 & 12.5 \\
\hline \multicolumn{3}{|l|}{ Sex } \\
\hline Male & 48.7 & 53.3 \\
\hline Female & 51.3 & 46.7 \\
\hline \multicolumn{3}{|l|}{ Annual household income $†$} \\
\hline$<\$ 20000$ & 23.5 & 8.7 \\
\hline$\$ 20000$ to 35000 & 37.0 & 44.2 \\
\hline$>35000$ & 39.6 & 47.2 \\
\hline \multicolumn{3}{|l|}{ Presence of children } \\
\hline Yes & 35.4 & 48.5 \\
\hline \multicolumn{3}{|l|}{ Stage of change $\dagger$} \\
\hline Precontemplation & 45.6 & 25.9 \\
\hline Contemplation & 38.0 & 55.1 \\
\hline Preparation & 16.4 & 19.0 \\
\hline \multicolumn{3}{|c|}{ Baseline cigarefte consumptiont } \\
\hline Occasional smoker & 11.1 & 35.1 \\
\hline Reg smoker, $1-10 /$ day & 15.3 & 21.0 \\
\hline Reg smoker, 11-20/day & 14.3 & 14.3 \\
\hline Reg smoker, $>20 /$ day & 59.3 & 29.7 \\
\hline \multicolumn{3}{|c|}{$\begin{array}{l}\text { *Percentages are from weighted analyses while counts are sample } \\
\text { frequencies. } \\
\text { tp }<0.05 \text {. }\end{array}$} \\
\hline
\end{tabular}

\section{Household bans and duration of quit attempts}

We examined whether a household ban might be associated with a longer time until relapse for these quit attempts. We found that stage of change at baseline modified the relapse rate $(\mathrm{p}=0.02)$. For respondents in preparation $(\mathrm{n}=82)$, a full ban on smoking was significantly associated with a lower relapse rate (hazard ratio $(\mathrm{HR})=0.5$ (95\% CI 0.2 to 0.9$)$ ) compared with those with no ban or a partial ban on smoking (fig 1). For those in precontemplation or contemplation $(\mathrm{n}=281)$, having a full ban was not significantly associated with the relapse rate ( $\mathrm{HR}=0.3(95 \% \mathrm{CI} 0.8$ to 2.0)) (fig 2). Addition of potential confounders to this Cox model did not appreciably change these estimates.

\section{Prevalence of sustained abstinence at follow up call}

About one fifth of the cohort $(\mathrm{n}=115)$ had been abstinent from smoking for at least one day at the follow up call. A total of $2.4 \%$ had quit less than seven days before, $16.1 \%$ at least seven days but less than three months before, $19.4 \%$ at least three but less than six months before, $30.1 \%$ at least six but less than 12 months before, and $32.0 \% 12$ months or more before the follow up call

\section{Household smoking bans, stage of change and cessation (sustained abstinence at follow up call)}

We found that the relation between ban status and sustained abstinence at follow up for at least seven and at least 90 days was modified by stage of change of the smoker at baseline $(\mathrm{p}=0.05$; table 3$)$. Among persons in precontemplation or contemplation, a full ban had no significant association with seven day quits. Among those in preparation with a full ban in place, however, the odds of a seven day quit at follow up were over four times greater than those with no ban or a partial ban, after adjustment for demographics and baseline consumption (OR $=4.4$ (95\% CI 1.1 to 18.7)). Respondents who were in cessation for at least 90 days at follow up followed a similar pattern: among smokers in the preparation stage, those with a full ban also had over four times the odds of quitting compared with those with no ban or a partial ban (table 3 ).

\section{DISCUSSION}

In this population based longitudinal study we observed that a full ban on household smoking was associated with a subsequent quit attempt, and was related to successful cessation among smokers who were in the preparation stage of the stage of change. A full household smoking ban was also associated with longer quit attempts for these respondents. For those not in the preparation stage, a full ban was essentially unassociated with increased odds of cessation or with longer quit attempts.

The findings of this study are subject to several limitations. With only participants' first name and baseline phone number, we were unable to trace many non-respondents and therefore had a substantial loss to follow up. However, the percentage of baseline respondents lost to follow up in this study is comparable to several of the population based longitudinal studies conducted by the US Census Bureau. ${ }^{19}$ Much of the attrition in those studies, as well as in ours, was caused by inability to locate respondents. This is an increasing problem owing to the high geographical mobility of the US population ( $16.5 \%$ of the population moved between March 1996 and March 1997). ${ }^{20}$ This mobility rate is consistent with our data-of the $45 \%$ lost to follow up, $10 \%$ refused, and 35\% could not be located after a two year period.

The comparability between our follow up subjects and the baseline group depended on factors such as age, race, income, and marital status, as shown in other studies on nonresponse. ${ }^{21-24}$ For these reasons, we used these variables to reweight the data to correct for some degree of non-response. This technique, however, also introduced somewhat greater variability into our estimates.

We had no way of validating the exposure (household smoking restrictions) or the outcomes (smoking cessation and other smoking behaviours) in this study. Self report of quit status, however, has been shown to be generally accurate except in special populations not represented in this study. ${ }^{25}$ We have previously suggested that differential misclassification of household smoking restrictions may occur contingent upon smoking status of the respondent. ${ }^{13}$ This was not a problem at baseline in this study as all the respondents were smokers. However, if smokers with bans at baseline were more likely to indicate quitting at follow up than smokers without bans through a tendency to report a socially desirable response, a bias could occur. ${ }^{26}$ The prospective nature of this study, however, may mitigate against this bias 
Table 2 Adjusted odds ratios for full household bans and one or more attempts to quit smoking between baseline and follow up* $\dagger$

\begin{tabular}{|c|c|c|c|c|c|c|}
\hline & \multicolumn{2}{|c|}{ No attempts to quit } & \multicolumn{2}{|c|}{$\begin{array}{l}\text { One or more } \\
\text { attempts to quit }\end{array}$} & \multirow[b]{2}{*}{ OR $\ddagger$} & \multirow[b]{2}{*}{$95 \% \mathrm{Cl}$} \\
\hline & $n$ & $\%$ & $n$ & $\%$ & & \\
\hline $\begin{array}{l}\text { No ban or partial ban } \\
\text { Full ban }\end{array}$ & $\begin{array}{l}146 \\
42\end{array}$ & $\begin{array}{l}38.5 \\
20.9\end{array}$ & $\begin{array}{l}241 \\
125\end{array}$ & $\begin{array}{l}61.5 \\
79.2\end{array}$ & $\begin{array}{l}\text { Reference } \\
2.0\end{array}$ & $\overline{1}-0$ to 3.9 \\
\hline
\end{tabular}

*Percentages are from weighted analyses while counts are sample frequencies.

†Six smokers had missing information on quit attempts, and five were excluded because of missing information on covariates.

$\ddagger$ Adjusted for age, employment status, and baseline consumption.

$\mathrm{Cl}$, confidence interval; OR, odds ratio.

to some degree, as exposure information (ban) was collected 21 months before follow up smoking status.

\section{Quit attempts, time until relapse, and smoking cessation}

Only a few other reports-all cross sectional in design-have investigated whether smoking related outcomes were associated with household bans. Gilpin et al, ${ }^{4}$ using data from a population based California tobacco survey, found that home smoking restrictions increased the likelihood of a quit attempt, and that given an attempt, a ban appeared to prolong time to relapse. Farkas et al also documented a fourfold increase in odds of a quit attempt associated with full household restrictions. ${ }^{6}$ Norman et al observed that household bans were related to an interest in quitting and the number of quit attempts in the previous year. ${ }^{5}$ Though these findings are consistent with ours, no investigation has been prospective in nature or has addressed whether smokers' stage of change might play a role in the relation between smoking restrictions and changes in smoking related behaviour.

Previous work has established the importance of the length of a quit attempt as a predictor of subsequent success in quitting, ${ }^{8}$ and we observed that a full ban tended to lengthen quit attempts for abstaining smokers. As noted, this finding was generally in agreement with Gilpin's study, although she did not note a modifying effect of stage of change. Other studies on relapse have noted that exposure to a smoker acts as a "cue" and promotes relapse, ${ }^{27-33}$ and that a non-smoking environment aids abstinence. ${ }^{34}$ A smoke-free household

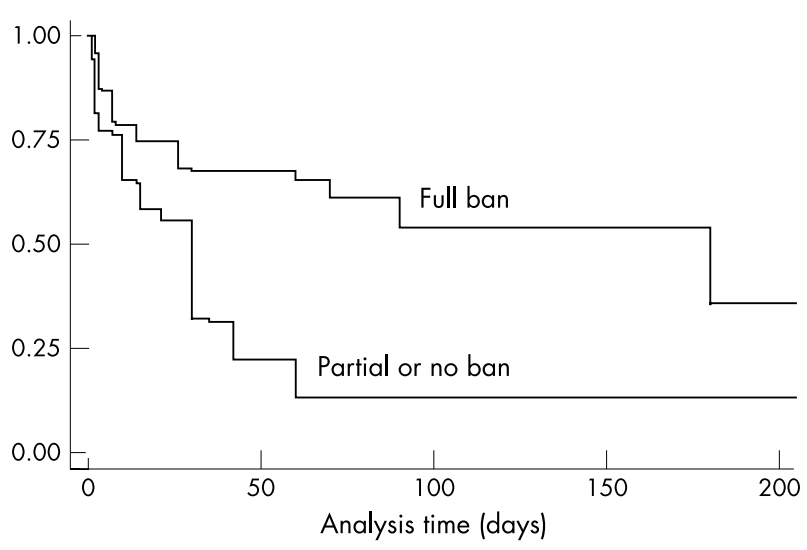

Figure 1 Kaplan-Meier survival curves for days to relapse to smoking by household ban status among 82 respondents in the preparation stage at baseline who had quit for at least one day during follow up. The analysis contains all smokers with a quit attempt; however, survival curves are truncated at six months to illustrate earlier, more frequent relapses better. One respondent had missing information on length of quit attempt. The difference between the curves is significant ( $p=0.02$ ). limits exposure to smoking cues from household members and visitors who might be smokers.

Only one of the above studies investigated an association between household bans and smoking cessation. Farkas et al, ${ }^{6}$ using data from the Current Population Survey, found that persons living in households with a full ban were almost twice as likely to have quit smoking in the previous year than those without a ban. Our results confirmed this association, but only within the subgroup of respondents who were in the preparation phase of the stage of change. The stage of change model has been used to match different types of interventions to smokers at different stages, thus more efficiently targeting groups susceptible to change. ${ }^{35-39}$ For example, the Clinical Practice Guidelines for Treatment of Tobacco Use and Dependence published by the US Public Health Service ${ }^{40}$ recommend assessment of every smoker for willingness to make a quit attempt in the next 30 days, and stage matched intervention. Under the guidelines, a provider employs pharmacotherapy and behavioural counselling for a patient in the preparation stage, but uses motivational intervention for a patient in the precontemplation or contemplation stages. Some telephone quit lines also screen callers for readiness to quit to deliver appropriate interventions. ${ }^{41}$ Our finding that the association between a household smoking ban and quitting is most pronounced among smokers in preparation could be useful in either of these settings if further research points toward a causal relation between bans and quitting.

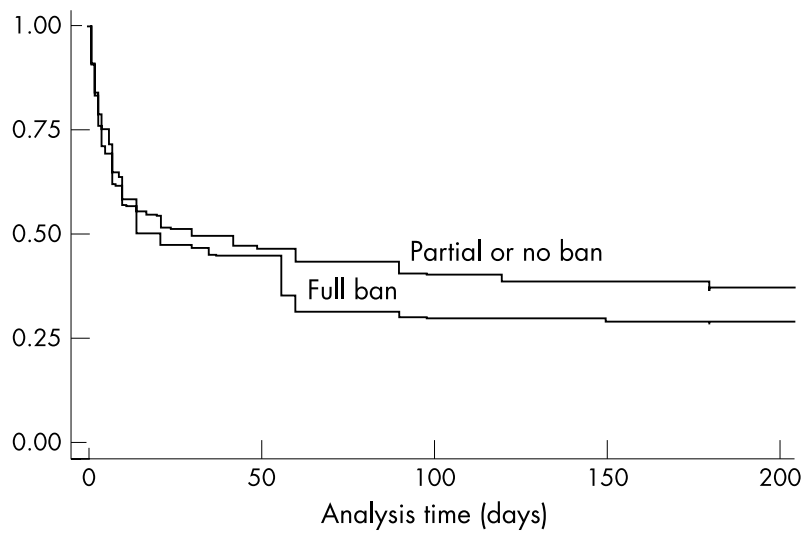

Figure 2 Kaplan-Meier survival curves for days to relapse to smoking by household ban status among 281 respondents in the precontemplation or contemplation stage at baseline who had quit for at least one day during follow up. The analysis contains all smokers with a quit attempt; however, survival curves are truncated at six months to illustrate earlier, more frequent relapses better. Seven respondents had missing information on length of quit attempt. The difference between the curves is not significant $(p=0.95)$. 
Table 3 Odds ratios for full household ban and smoking cessation for at least seven and at least 90 days, within strata of stage of change*

\begin{tabular}{|c|c|c|c|c|c|c|c|c|c|c|c|c|}
\hline & \multicolumn{6}{|c|}{ Among those in precontemplation or contemplation } & \multicolumn{6}{|c|}{ Among those in preparation } \\
\hline & \multicolumn{2}{|c|}{ Did not quit } & \multicolumn{2}{|c|}{ Quit at least 7 days } & \multirow[b]{2}{*}{ ORt‡ } & \multirow[b]{2}{*}{$95 \% \mathrm{Cl}$} & \multicolumn{2}{|c|}{ Did not quit } & \multicolumn{2}{|c|}{ Quit at least 7 days } & \multirow[b]{2}{*}{ ORt‡ } & \multirow[b]{2}{*}{$95 \% \mathrm{Cl}$} \\
\hline & $n$ & $\%$ & $\mathrm{~N}$ & $\%$ & & & $n$ & $\%$ & n & $\%$ & & \\
\hline \multirow[t]{3}{*}{$\begin{array}{l}\text { No ban or } \\
\text { partial ban } \\
\text { Full ban }\end{array}$} & $\begin{array}{l}284 \\
99\end{array}$ & $\begin{array}{l}82.1 \\
83.8\end{array}$ & $\begin{array}{l}48 \\
27\end{array}$ & $\begin{array}{l}17.9 \\
16.2\end{array}$ & $\begin{array}{l}\text { Reference } \\
0.9\end{array}$ & $\overline{0} .4$ to 2.3 & $\begin{array}{l}38 \\
24\end{array}$ & $\begin{array}{l}84.8 \\
50.8\end{array}$ & $\begin{array}{l}13 \\
17\end{array}$ & $\begin{array}{l}15.1 \\
49.2\end{array}$ & $\begin{array}{l}\text { Reference } \\
4.4\end{array}$ & $\overline{1.1}$ to 18.7 \\
\hline & \multicolumn{2}{|c|}{ Did not quit } & \multicolumn{2}{|c|}{ Quit at least 90 days } & & & \multicolumn{2}{|c|}{ Did not quit } & \multicolumn{2}{|c|}{ Quit at least 90 days } & & \\
\hline & $\mathbf{n}$ & $\%$ & $\mathbf{N}$ & $\%$ & $\mathrm{OR}+\S$ & $95 \% \mathrm{Cl}$ & $\mathrm{n}$ & $\%$ & $\mathrm{n}$ & $\%$ & OR†§ & $95 \% \mathrm{Cl}$ \\
\hline $\begin{array}{l}\text { No ban or } \\
\text { partial ban } \\
\text { Full ban }\end{array}$ & $\begin{array}{l}288 \\
100\end{array}$ & $\begin{array}{l}83.2 \\
84.7\end{array}$ & $\begin{array}{l}44 \\
26\end{array}$ & $\begin{array}{l}16.8 \\
15.4\end{array}$ & $\begin{array}{l}\text { Reference } \\
1.0\end{array}$ & $\overline{0} .4$ to 2.4 & $\begin{array}{l}38 \\
24\end{array}$ & $\begin{array}{l}91.3 \\
66.9\end{array}$ & $\begin{array}{l}11 \\
11\end{array}$ & $\begin{array}{l}8.7 \\
33.1\end{array}$ & $\begin{array}{l}\text { Reference } \\
4.3\end{array}$ & $\overline{0} .9$ to 21.2 \\
\hline
\end{tabular}

*Percentages are from weighted analyses while counts are sample frequencies.

†All estimates adjusted for age, race, educational status, and baseline cigarette consumption. For the seven day analysis, eight respondents were excluded for missing data on covariates, and seven were excluded as they had quit for less than seven days. For the 90 day analysis, eight respondents were excluded for missing data, and 23 were excluded as they had quit for less than 90 days.

flnteraction for seven day quits, $p=0.05$

§Interaction for 90 day quits, $\mathrm{p}=0.08$.

$\mathrm{Cl}$, confidence interval; OR, odds ratio.

We do not know from this study whether the home restrictions facilitated movement into the preparation phase or vice versa, as information on both of these variables was collected from the cross sectional baseline survey. On the one hand, household restrictions may lead to preparation by decreasing the convenience of smoking; on the other, those in preparation and already thinking of quitting may be more inclined to establish a household restriction. Although further studies might clarify the direction of this association for purposes of public health interventions, the fact remains that in either event the combination of the ban and preparation was more highly associated with cessation than the preparation stage alone.

\section{Conclusions}

We found that household smoking bans were associated with increased quit attempts. Furthermore, full bans were associated with a longer duration of those attempts and more frequent sustained abstinence at follow up, as long as the smoker intended to quit in the short run. Further research on this link is important because of potential applicability in both client focused settings and population based approaches. In clinical and help-line settings where smokers are screened for readiness to quit, health care providers could encourage household restrictions, if these restrictions continue to show promise as an aid to quitting.

\section{What this paper adds}

Several cross sectional studies have documented an association between home smoking bans and reduction in smoking related behaviours (lighter smoking, cessation, reduced risk of relapse). To our knowledge, however, no report has examined this relation longitudinally.

This follow up study suggests that among smokers who are preparing to quit, those living with full bans may subsequently quit more often than those living without them. If further research should show this association to be causal, the promotion of smoking bans could be useful in both client focused and population based approaches to smoking cessation.
Also, if further studies confirm the relation, mass media messages that target smokers and non-smokers alike could emphasise both the secondhand smoke protection message and the possibility that restrictions might assist the smoker in the long process of successfully becoming a non-smoker.

\section{Authors' affiliations}

B A Pizacani, M J Stark, Oregon Department of Human Services, Portland, Oregon, USA

T D Koepsell, University of Washington, Department of Epidemiology, Seattle, Washington, USA

D P Martin, B Thompson, University of Washington, Department of Health Services

P Diehr, University of Washington, Department of Biostatistics

\section{REFERENCES}

1 US Department of Health and Human Services. Health effects of exposure to environmental tobacco smoke: the report of the California Environmental Protections Agency. Bethesda, MD: National Institutes of Health, National Cancer Institute, 1999 (Smoking and Tobacco Control Monograph No 10).

2 Chapman S, Borland R, Scollo M, et al. The impact of smoke-free workplaces on declining cigarette consumption in Australia and the United States. Am J Public Health 1999;89:1018-23.

3 Glasgow RE, Cummings KM, Hyland A. Relationship of worksite smoking policy to changes in employee tobacco use: findings from COMMIT. Tobacco Control 1997;6(suppl 2):S44-8.

4 Gilpin EA, White MM, Farkas AJ, et al. Home smoking restrictions: which smokers have them and how they are associated with smoking behavior. Nicotine Tob Res 1999:1:153-62.

5 Norman GJ, Ribisl KM, Howard-Pitney B, et al. The relationship between home smoking bans and exposure to state tobacco control efforts and smoking behaviors. Am J Health Promot 2000;15:81-8.

6 Farkas AJ, Gilpin EA, Distefan JM, et al. The effects of household and workplace smoking restrictions on quitting behaviours. Tobacco Control 1999;8:261-5

7 Pierce JP, Farkas AJ, Gilpin EA. Beyond stages of change: the quitting continuum measures progress towards successful smoking cessation. Addiction 1998;93:277-86.

8 Farkas AJ, Pierce JP, Zhu SH, et al. Addiction versus stages of change models in predicting smoking cessation. Addiction 1996;91:1271-80.

9 Hennrikus DJ, Jeffery RW, Lando HA. Occasional smoking in a Minnesota working population. Am J Public Health 1996;86:1260-6.

10 Gilpin EA, Pierce JP, Farkas AJ. Duration of smoking abstinence and success in quitting. J Natl Cancer Inst 1997;89:572-6.

11 Gilpin E, Cavin SW, Pierce JP. Adult smokers who do not smoke daily. Addiction 1997:92:473-80.

12 Hughes JR. Reduced smoking: an introduction and review of the evidence. Addiction 2000;95(suppl 1):S3-7.

13 Pizacani BA, Martin, DP, Stark, MJ, et al. Household smoking bans: which households have them and do they work? Prev Med 2003;36:99-107.

14 Prochaska JO, Velicer WF. The transtheoretical model of health behavior change. Am J Health Promot 1997; 12:38-48. 
15 DiClemente CC, Prochaska JO, Fairhurst SK, et al. The process of smoking cessation: an analysis of precontemplation, contemplation, and preparation stages of change. J Consult Clin Psychol 1991;59:295-304.

16 Brick JM, Kalton G. Handling missing data in survey research. Stat Methods Med Res 1996:5:215-38.

17 Potter FJ, lannacchione VG, Mosher WD, et al. Sample design, sampling weights, imputation, and variance estimation in the 1995 National Survey of Family Growth. Vital Health Stat 2 1998:1-63.

18 StataCorp. Stata statistical software: release 6.0. College Station, Texas: Stata Corporation, 1999.

19 US Census Bureau. Comparing response rates for SPD, PSID, and NLSY. http://www.sipp.census.gov/spd/workpaper/spd-comp.htm

20 Current Population Survey. Geographical mobility of people 1 year old and older, by sex, between March 1996 and March 1997. http:// www.bls.census.gov/cps/pub/1997/mobility.htm

21 Psaty BM, Cheadle A, Koepsell TD, et al. Race- and ethnicity-specific characteristics of participants lost to follow-up in a telephone cohort. Am J Epidemiol 1994:140:161-71.

22 Siddiqui O, Flay BR, Hu FB. Factors affecting attrition in a longitudinal smoking prevention study. Prev Med 1996;25:554-560.

23 Shahar E, Folsom AR, Jackson R. The effect of nonresponse on prevalence estimates for a referent population: insights from a population-based cohor study. Atherosclerosis Risk in Communities (ARIC) Study Investigators. Ann Epidemiol 1996;6:498-506.

24 Benfante R, Reed D, MacLean C, et al. Response bias in the Honolulu Heart Program. Am J Epidemiol 1989;130:1088-100.

25 Patrick DL, Cheadle A, Thompson DC, et al. The validity of self-reported smoking: a review and meta-analysis. Am J Public Health 1994:84:1086-93.

26 Wynder EL, Higgins IT, Harris RE. The wish bias. J Clin Epidemiol 1990;43:619-21.

27 Brownell KD, Glynn TJ, Glasgow R, et al. Interventions to prevent relapse. Health Psychol 1986;5(suppl):53-68

28 Lichtenstein E, Weiss SM, Hitchcock JL, et al. Patterns of smoking relapse. Health Psychol 1986;5(suppl):29-40.
29 Garvey AJ, Bliss RE, Hitchcock JL, et al. Predictors of smoking relapse among self-quitters: a report from the Normative Aging Study [published erratum appears in Addict Behav 1992 Sep-Oct;17:513]. Addict Behav 1992; 17:367-77.

30 Curry S, Thompson B, Sexton M, et al. Psychosocial predictors of outcome in a worksite smoking cessation program. Am J Prev Med 1989;5:2-7.

31 Marlatt GA, Curry S, Gordon JR. A longitudinal analysis of unaided smoking cessation. J Consult Clin Psychol 1988;56:715-20.

32 Klesges RC, Brown K, Pascale RW, et al. Factors associated with participation, attrition, and outcome in a smoking cessation program at the workplace. Health Psychol 1988;7:575-89.

33 Stevens VJ, Hollis JF. Preventing smoking relapse, using an individually tailored skills-training technique. J Consult Clin Psychol 1989;57:420-4

34 Horwitz MB, Hindi-Alexander M, Wagner TJ. Psychosocial mediators of abstinence, relapse, and continued smoking: a one-year follow-up of a minimal intervention. Addict Behav 1985;10:29-39.

35 Velicer WF, Prochaska JO, Bellis JM, et al. An expert system intervention for smoking cessation. Addict Behav 1993;18:269-90.

36 Prochaska JO, Goldstein MG. Process of smoking cessation. Implications for clinicians. Clin Chest Med 1991; 12:727-35.

37 Strecher VJ, Kreuter M, Den Boer DJ, et al. The effects of computer-tailored smoking cessation messages in family practice settings. J Fam Pract 1994;39:262-70.

38 Wang WD. Feasibility and effectiveness of a stages-of-change model in cigarette smoking cessation counseling. J Formos Med Assoc 1994;93:752-7.

39 Goldberg DN, Hoffman AM, Farinha MF, et al. Physician delivery of smokingcessation advice based on the stages-of-change model. Am J Prev Med 1994; 10:267-74.

40 Fiore MC, Bailey WC, Cohen SJ, et al. Treating tobacco use and dependence. Clinical practice guideline. Rockville, MD: US Department of Health and Human Services, Public Health Service, 2000.

41 Zhu SH, Anderson CM, Johnson CE, et al. A centralised telephone service for tobacco cessation: the California experience. Tobacco Control 2000;9:1148-55. 